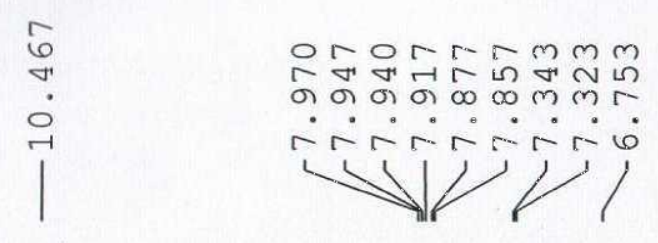

DR. HAROON/DR. HINA/MHH . I . 35

$1 \mathrm{H}$

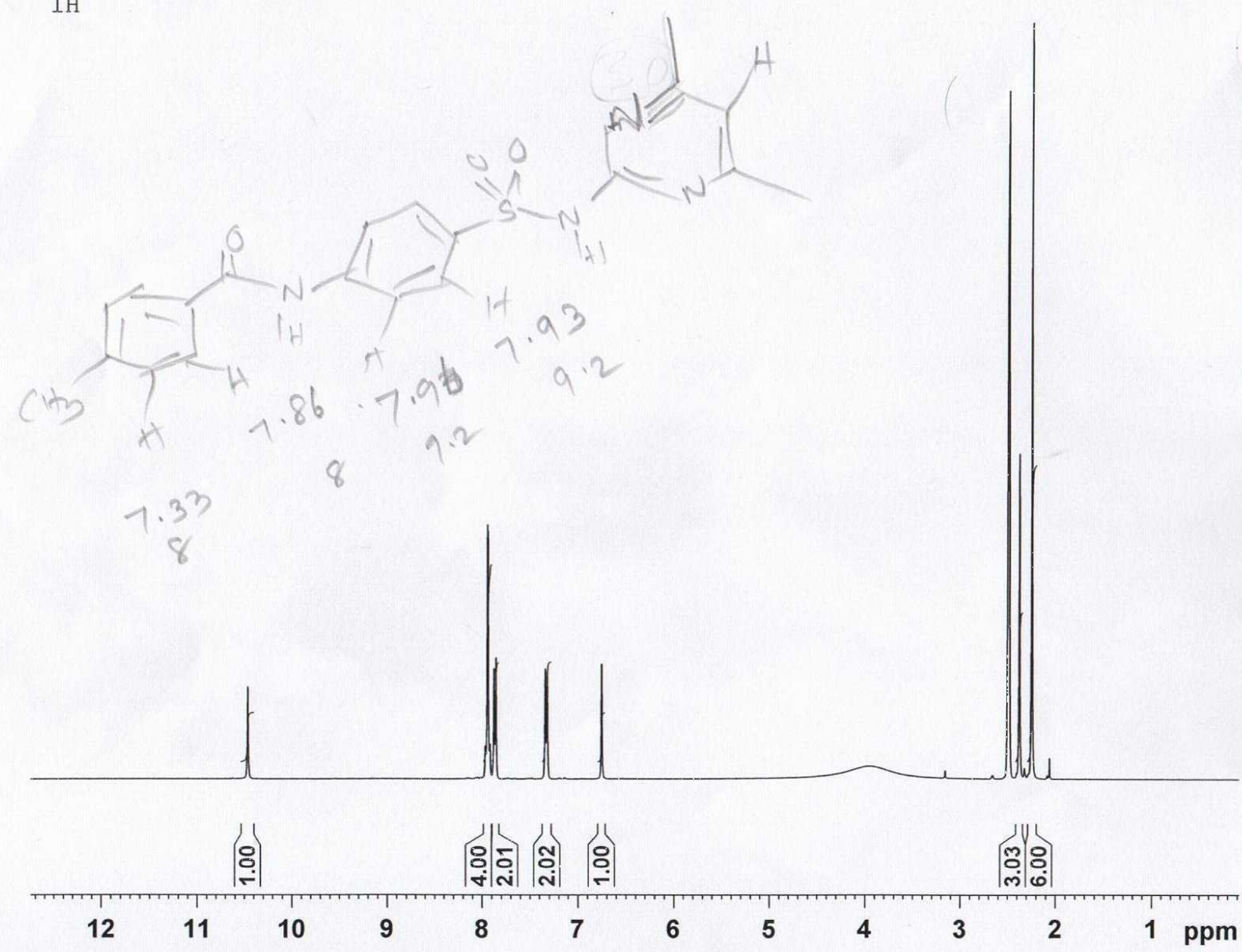


DR. HAROON/DR . HINA/MHH . I . 35

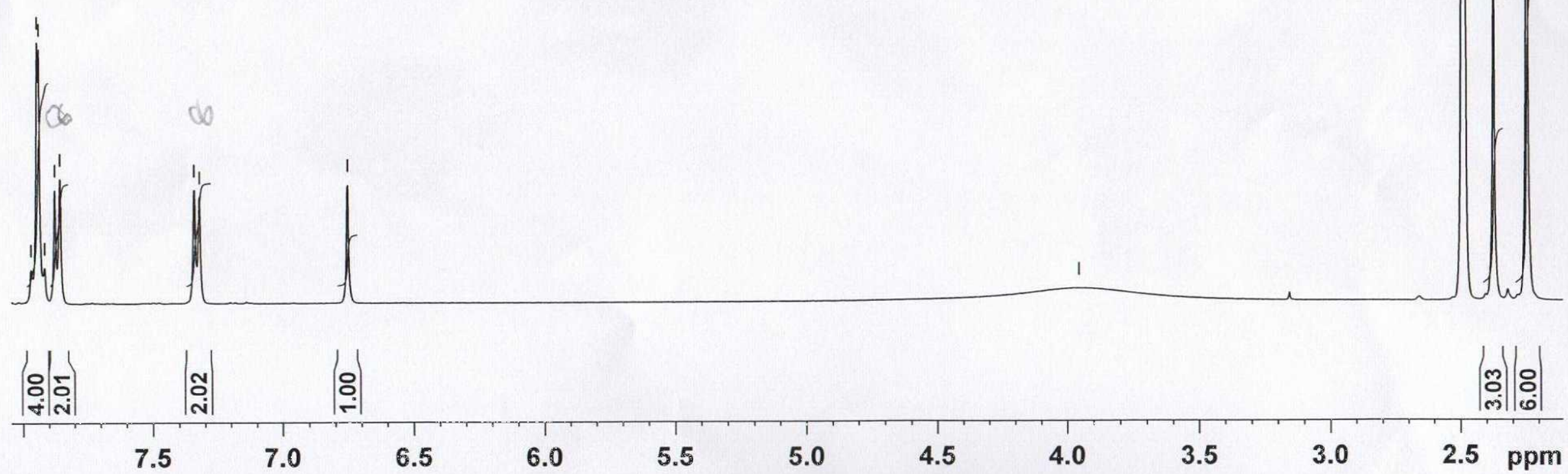


ำ

hrar

$11 / 11$

in

DR . HAROON/DR . HINA/MHH . I . 35

$1 \mathrm{H}$
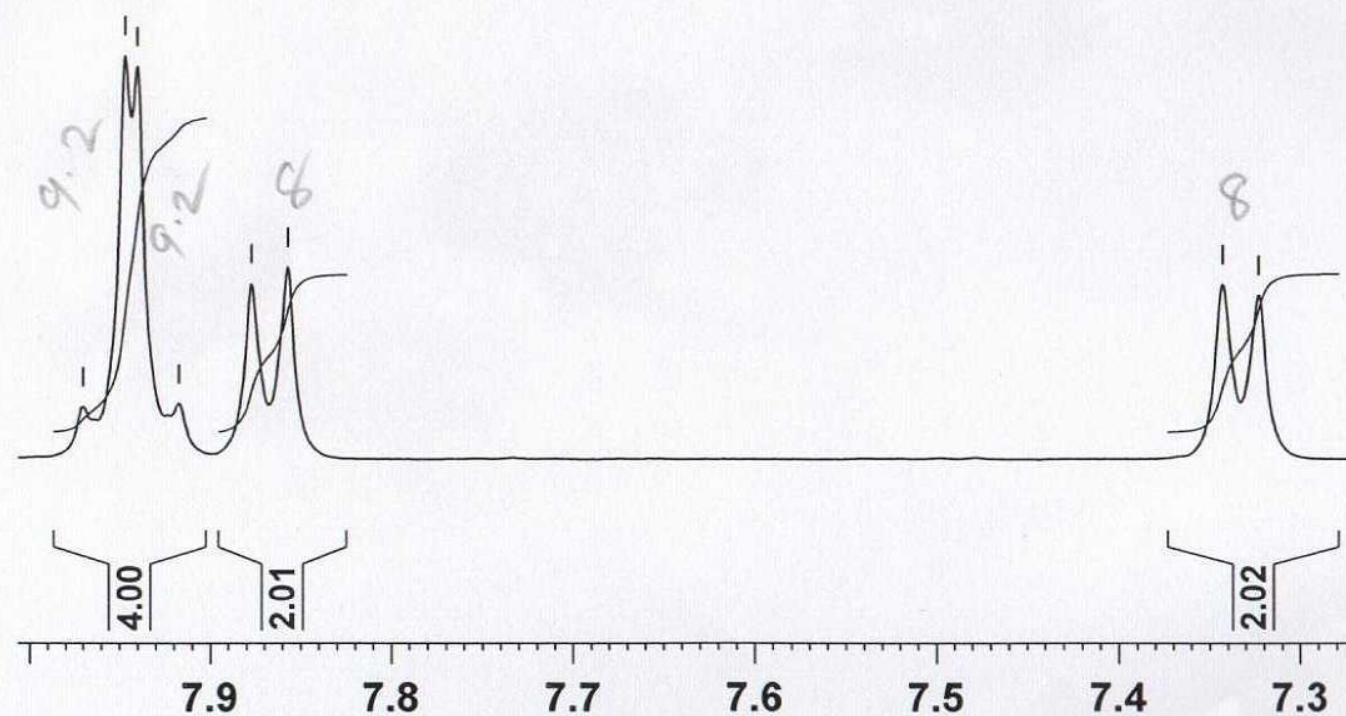

7.8

7.7

7.5

$\begin{array}{ll}7.4 & 7.3\end{array}$ 
File: MHH-I-35

Sample: DR.M.H.HAROON /DR. IQBAL

Instrument: JEOL MS $600 \mathrm{H}-1$

Date Run: 02-10-2017 (Time Run: 12:54:53)

Ionization mode: EI+

\section{Scan: 21}

Base: $\mathrm{m} / \mathrm{z}$ 332; $99.5 \%$ FS TIC: $\mathbf{5 4 6 7 0 3 4}$

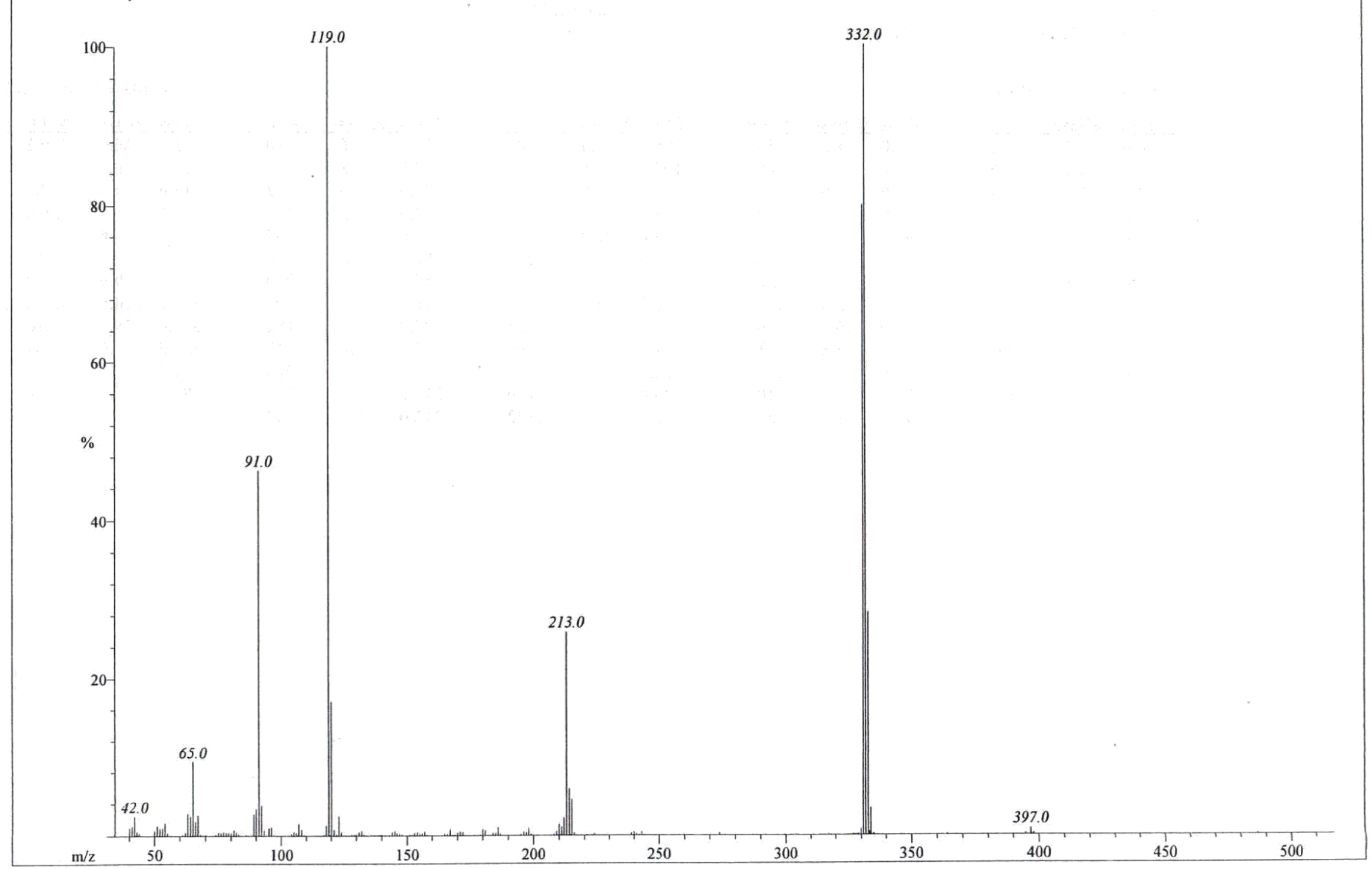

\section{R.T.: 1.77}

450 
I. C.C.B.S., University of Karachi Analytical Laboratory - Pakistan

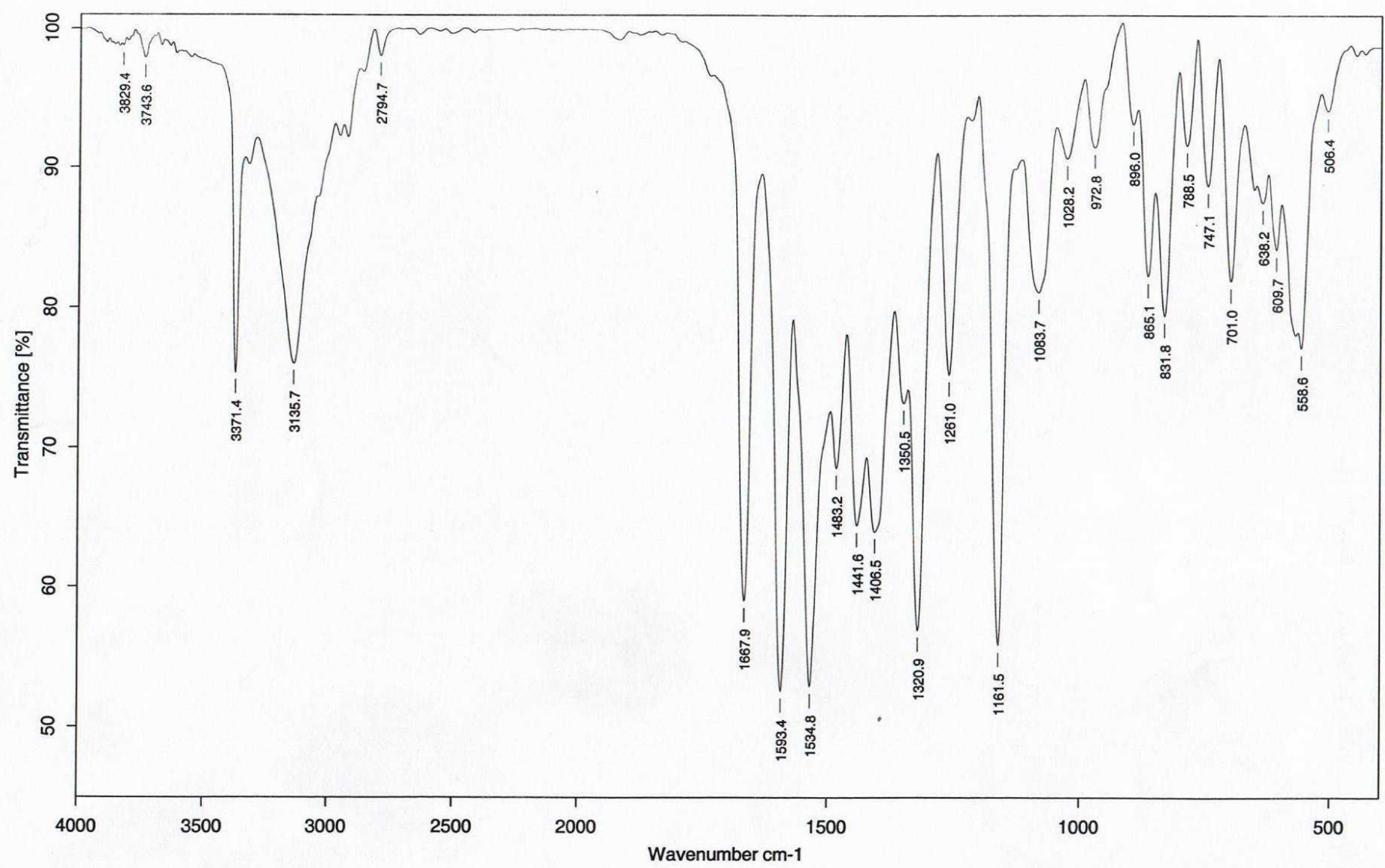

\begin{tabular}{|c|c|}
\hline Sample: $\quad$ MHH-1-35/Dr.Haroon & Spectrum : MHH-1-35.0 (in D:IIRSTUDENT) \\
\hline Measured : $30 / 01 / 2017$ on VECTOR22 & Technic : Solid \\
\hline Resolution : $4 \mathrm{~cm}-1$ ( 10 scans ) & Analyst : Zubair Ahmad/ Jamshed \\
\hline
\end{tabular}




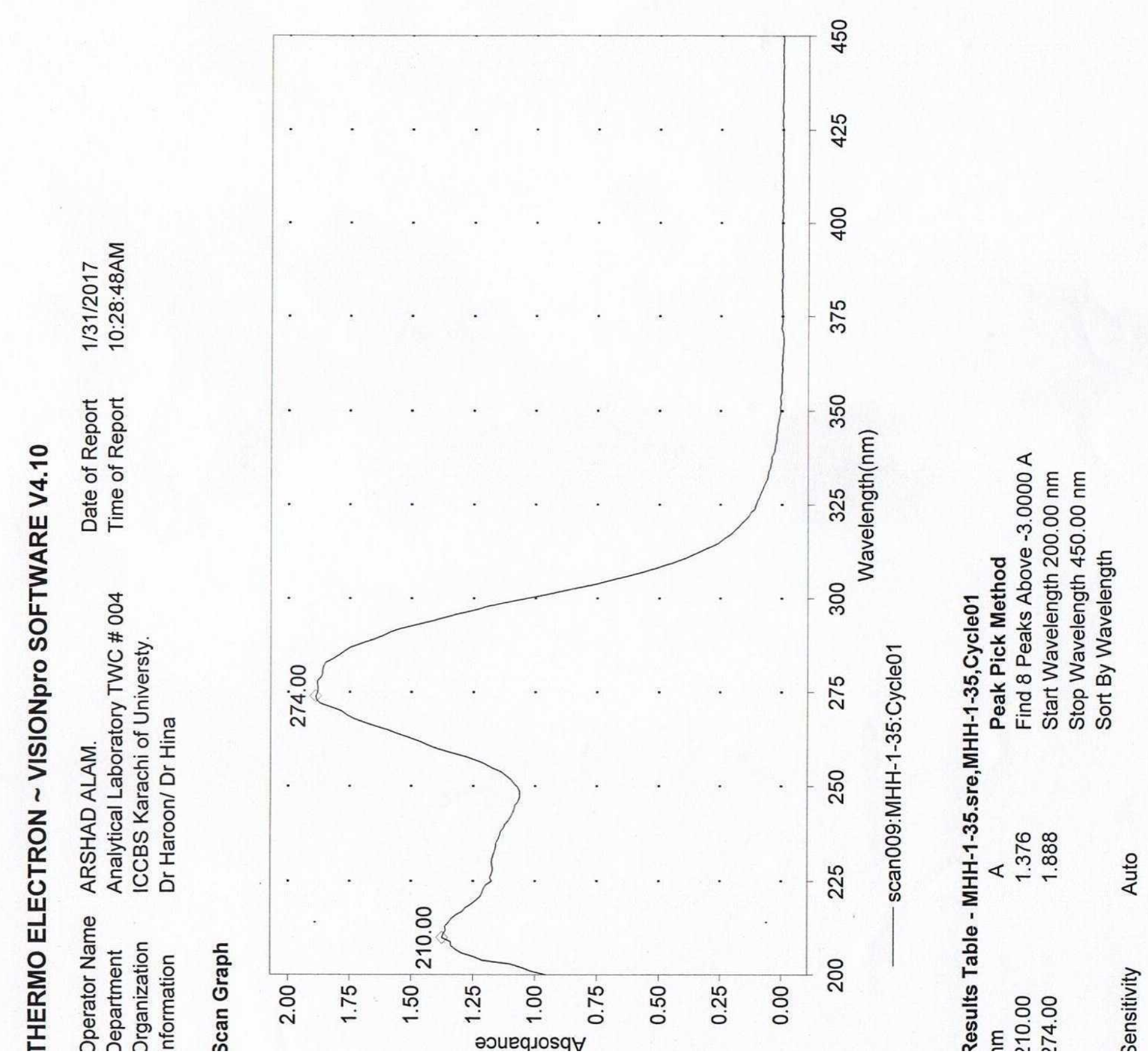

